\title{
The Relationship Between Internet Usage, Socioeconomic Status, Subjective Health and Social Status
}

\begin{abstract}
Annan Saeed Khan, Atta ur Rahman ${ }^{1}$, Laila Taskeen Qazi ${ }^{2}$
Abstract

This study strives to analyze the concept of digital divide within the context of Pakistan. In this study, the differential internet usage has been studied through the impact of age, income, and having an online job on the average daily usage of internet per person in Pakistan. A questionnaire was developed for the survey and data was collected through purposive sampling technique. A total of 500 filled questionnaires were returned. The findings of the survey report a higher use of internet among young people as compared to aged people. Furthermore, higher income class within the sample is found to be a major user of internet, and having an online job increases the internet usage hours by manifolds. In addition, the findings of the study also depict that youngsters are more inclined towards the use of social websites which is also a source of social satisfaction for its users.
\end{abstract}

Keywords: Digital divide, internet, survey, website.

\section{Introduction}

Internet is a technology that has the most profound effect on human functioning. It was commercialized in 1995, removing last restrictions on its use to carry commercial traffic. This resulted in using internet as an added facility in almost all phases of life. Internet services (social sites, e-mails, etc.) provide users with a wide range of benefits and shortcomings, many of which the users are aware of; but all use it to fulfill certain goals. This means that the key to using internet is not technology but the individuals themselves. In addition, people's perceptions about using internet are shaped by the existing value system of a society. Pakistan introduced internet in the early 1990's. According to the International Telecommunications Union, there were 133,900 internet users in 2000 or just $0.1 \%$ of the 164 million people in Pakistan. By 2006 , internet use had grown to 12 million users or $7.2 \%$ of the population. By 2011, this usage had further grown up to 31 million users or $17.6 \%$ of the total population (ICT Indicators, 2010).

Regradless of the increasing trend of internet usage, the economic and social

1 Associate Professor, Institute of Management Sciences, Peshawar. Email: attaurrahman@imsciences. edu.pk

2 Lecturer, Institute of Management Sciences, Peshawar. Email: laila.taskeen@imsciences.edu.pk 
inequality can still be seen in the society in terms of access, use and skill requirements for the internet usage. The technological inequailty refers to the concept of digital divide which explains the socioeconomic and other disparities between people who have opportunites to benefit from digital technologies and those who do not. The idea of digital divide is a complex and dynamic phenomenon which is typically measured through the difference between those who have the access to the web versus those who do not.

However, several conceptualizations of digital divide have been presented in the literature (Van Deursen \& Van Dijk, 2014; Sui, Goodchild, \& Elwood, 2013). Through these conceptualizations the literature indentifies four main areas of discussion including attitudes, access, skills and type of usage. The focus of this study is the differential internet usage across three different dimensions including socioeconomic status, subjective health, and social status. The primary motivation of this study emerged from the fact that having physical and material access and necessary skills to apply digital media is not enough to determine the differential internet usage. Rather the literature has identified separate grounds and determinants of differential internet usage encompassing factors such as socioeconomic status, user age, content, frequency, length of time the internet is used, and the type of activities performed over the internet. On the basis of the said determinants, this paper focuses on understanding the patterns of differential internet usage across the user age, his socioeconomic status, health conditions and social status. Using a cross-sectional data set, empirical findings of the study are generated through the application of Chi-square test. In order to achieve the said objectives the rest of the study has been organized as follows. Section 2 provides a detailed review of the related literature. Section 3 gives an account of the methodology adopted to achieve the said objectives. Section 4 contains a detained discussion pertaining to empirical findings of the study. Section 5 provides the conclusion of the study.

\section{Literature Review}

Digital Divide is defined as the gap between the geographical areas, individuals, households and corporations on the basis of their ability to access Information and Communication Technologies (ICT) ${ }^{3}$. Also the idea of Digital Divide describes the difference between the use of internet for a wide variety of activities by individuals, households and corporations. The concept of Digital Divide strives to translate social inequalities into digital discriminations. People with different socioeconomic status tend to depict differencing attitudes towards the usage of technology (Van Deursen \& Van Dijk, 2014; Sui, Goodchild, \& Elwood, 2013).

3 World Internet Project. (2012). Los Angeles, CA. http://www.worldinternetproject.net 
Analyzing the theories of media, the knowledge gap hypothesis serves as a forerunner of the digital divide concept. The knowledge gap hypothesis says that when the flow of mass media information increases in the social system, those segments of the society which are at a higher socioeconomic status tend to absorb this information at a higher rate as compared to the lower socioeconomic status segments of the population (Tran, 2013). The knowledge gap hypothesis applies to the traditional sources of mass media including newspaper, radio, television and telephone. The knowledge gap hypothesis cannot be directly applied upon internet as the internet usage requires specific set of skills as well as enabling technologies as compares to simply reading newspaper or watching television (Pearce \& Rice, 2013).

The functionality of radio, television, newspaper and telephone is little different as compared to the internet due to which the internet creates a usage gap which is different from the knowledge gap (Pearce $\&$ Rice, 2013). Usage gap is a broader area of research which talks about differential in uses and activities pertaining to daily life. The usage gap hypothesis is based on the assumption that there are certain internet activities that are more beneficial and advantageous as compared to other activities (Hashim, 2015; Zhang, 2013). Such beneficial activities over the internet provide the users with an opportunity to excel in career, education, work and societal positions rather than other activities that are basically consumptive or entertaining. Here it can be conclude that the usage gap hypothesis enables the users to build more social, cultural and economical capital through the internet (Ngai, Tao, \& Moon, 2015).

The concept of differential internet usage based on the usage gap hypothesis can be explained through several socio-demographic variables (Terlutter, Bidmon, \& Röttl, 2014). Age is one of the most important variables that explain the differential usage of internet among different social classes. The literature reveals that young adults are more active users of internet as compared to the older age people. The younger generations take the lead in using communication tools for chatting and instant messaging and also for entertainment and downloading music. The studies also reveal that older people are primarily involved in online purchases, emailing and searches for health issues (Kuss, Van Rooij, Shorter, Griffiths, \& van de Mheen, 2013).

Moreover, the socio-economic status is another important determinant of internet usage. The studies in the literature indicate that people at a higher socio-economic status tend to use internet more as compare to those at a lower socioeconomic status. People at a higher socioeconomic status are more effective in using internet productively and also for increasing their economic wealth. However socioeconomic status is a multifaceted concept measured through several variables like educational level, employment status and income levels. Here the education level attained and income is strongly correlated. However income has also been found to have an independent 
effect on internet usage. It is found out that people with high income tend to be involved in using internet for news, for searching jobs, product information and also for work. On the other hand people with low income are found to be more inclined towards using internet for entertainment and downloading (Ritzhaupt, Liu, Dawson, \& Barron, 2013).

Furthermore research reveals that people who are experienced in internet usage are more involved in suing internet for personally advantageous activities such as acquiring online jobs, getting health care information and developing social ties and relationships over the internet (Nadkarni \& Hofmann, 2012). Apparently there are two motives behind the internet activities (Pontes, Szabo, \& Griffiths, 2015). First the internet is used by young people for entertainment and for social networking. Second internet is used by highly educated mature people for information and work purposes such as online jobs. Smith and Brenner (2012) indicated that the internet has enabled people in USA to avoid isolation as the social networking forums provide people with the opportunity to develop social ties and to develop large social networks (Heo, Oh, Subramanian, Kim, \& Kawachi, 2014). Lennon, Rentfro, and Curran (2011) found out that social networking in young people enables them to develop new relationships and new social ties.

Neter and Brainin (2012) explored the use of internet for the purpose of extending health literacy. It is revealed that eHealth literacy allows people to hunt Health information pertaining to their specific health issues over the internet. The findings indicate that people who are more eHealth literate tend to generate more productive results of the eHealth information retrieved through the internet (Kontos, Blake, Chou, \& Prestin, 2014).

A detailed review of the literature reveals that several dimensions of socioeconomic research have been discussed in detail in past researches however for an underdeveloped country like Pakistan a research pertaining to digital divide and differential internet usage gap hypothesis is a new area of research. Therefore this study strives to analyze the socioeconomic dimensions of digital divide and internet usage gap hypothesis within the context of Pakistan. The next section provides a detailed discussion of the methodology employed in this study.

\section{Methodology}

Data is collected through a survey of self-made structured questionnaires having a set of close ended questions. The reliability of the questionnaires is checked using Cronbach's Alpha test and is found to be 0.62 . The sample consists of people from all walks of life, students and faculty of major universities in cities like Peshawar, 
Rawalpindi, Islamabad and Lahore. The age of the respondents was not kept in a range, i.e. anybody who was a consumer of internet was taken as a fit respondent for the survey. A sample of 500 respondents was taken $(n=500)$ which comprised of 298 males and 202 females. The data is analyzed using Chi-square test of independence.

\subsection{Hypotheses}

This study strives to investigate the relationship of internet usage with the socio-economic conditions and income of its users. The study also intends to investigate the relationship of differential internet usage users' social needs and health. On the basis of the said objective the following hypotheses have been tested in this study.

Socioeconomic status is a digital divide research variable intending to explain the social status of the respondents in monetary terms. The literature presents digital division specifically between the rich and the poor. The understanding, skills and access of the respondents towards the internet technologies is inevitable due to the differential in the economic wealth of the respondents. Therefore rich and economically sound people are expected to use internet more as compared to the poor people as hypothesized below,

$\mathrm{H}_{1}$ : there is an association between internet usage and socioeconomic status

Moreover people with greater internet usage tend to have a greater access to the online information databases pertaining to different issues in life such as health. Therefore it can also be hypothesized that as people use more internet they can use the available information related to health issues productively.

$\mathrm{H}_{2}$ : there is an association between internet usage and Subjective Health

Additionally increased internet usage is also attributable to the increase in the number of social networking websites and forums which help people to develop social connections online and improve upon their social status. Therefore a relationship between internet usage and social status can also be hypothesized as under,

$\mathrm{H}_{3}$ : there is an association between internet usage and Social Status

The study is based on a detailed analysis of what effects and trends the internet has caused in our lives, whether it is on the social front or in terms of health, all major relations and trends that could be linked to the internet and user have been highlighted. Secondly internet usage and its trends regarding age, economic conditions and social area, has been searched out in this study. 


\section{Analysis and Results}

This section of the study discusses its empirical results.

Table 1: Age and Hourly Internet Usage

\begin{tabular}{|c|c|c|c|c|}
\hline \multirow{2}{*}{ Age Range/yrs } & \multicolumn{3}{|c|}{ Hours usage/day } & \multirow{2}{*}{ Total } \\
\cline { 2 - 5 } & Low & Medium & High & \\
\hline $11-20$ & 68 & 36 & 32 & 136 \\
\hline $21-30$ & 118 & 127 & 88 & 333 \\
\hline $31-40$ & 11 & 6 & 4 & 21 \\
\hline 41 and above & 7 & 1 & 0 & 8 \\
\hline Total & 204 & 170 & 124 & 498 \\
\hline & Value & df & Asymp. Sig. (2-sided) \\
\hline Pearson Chi-Square & 18.382 & 8 & \multicolumn{2}{c}{.019} \\
\hline Likelihood Ratio & 20.359 & 8 & 009 \\
\hline
\end{tabular}

\subsection{Age of User and their Internet Consumption (hours per day)}

The results, as evident from Table 1, show a Pearson Chi-Square value of with a $\mathrm{p}$ value $=0.019$ which is less than the significance level of $5 \%$. This indicates a significant association between age of the respondents and hours of internet usage .

Table 2: Income and Expenditure on Internet Package

\begin{tabular}{|c|c|c|c|c|}
\hline \multirow{2}{*}{ Income/Rs. } & \multicolumn{2}{|c|}{ Expenditure on Packages Rs./monthly } & \multirow{2}{*}{ Total } \\
\cline { 2 - 5 } & $300-1000$ & $1100-1999$ & $2000-2500$ & \\
\hline $100-2000$ & 39 & 56 & 16 & 111 \\
\hline $2100-5000$ & 50 & 91 & 32 & 173 \\
\hline $5100-10,000$ & 28 & 56 & 29 & 113 \\
\hline $11,000-30,000$ & 11 & 31 & 5 & 47 \\
\hline $31,000-80,000$ & 7 & 15 & 13 & 35 \\
\hline $81,000-120,000$ & 3 & 12 & 2 & 17 \\
\hline Total & 138 & 261 & 97 & 496 \\
\hline & Value & df & Asymp. Sig. (2-sided) \\
\hline Pearson Chi-Square & 20.895 & 12 & \multicolumn{2}{|c}{.052} \\
\hline Likelihood Ratio & 21.006 & 12 & \multicolumn{3}{|l}{} \\
\hline
\end{tabular}




\subsection{Association Between Income Range and Expenditure on Internet Packages}

The results, as evident from Table 2, show a Pearson Chi-Square value of with a $\mathrm{p}$-value $=0.052$ which is less than the significance level of $10 \%$. This indicates a

Table 3: Online Jobs and Hours of Internet Usage

\begin{tabular}{|c|c|c|c|}
\hline \multirow{2}{*}{ Hours Used/ day } & \multicolumn{2}{|c|}{ Job } & \multirow{2}{*}{ Total } \\
\cline { 2 - 3 } & No & Yes & 205 \\
\hline $1-2$ & 195 & 10 & 170 \\
\hline $3-9$ & 148 & 22 & 124 \\
\hline 10 and above & 98 & 26 & 499 \\
\hline Total & 441 & 58 & Asymp. Sig. (2-sided) \\
\hline & Value & df & .000 \\
\hline Pearson Chi-Square & 19.908 & 2 & .000 \\
\hline Likelihood Ratio & 20.373 & 2 & \\
\hline
\end{tabular}

significant association between income and expenditure on internet package.

\subsection{Online Jobs and the Usage of internet}

The results, as evident from Table 3, show a Pearson Chi-Square value of

Table 4: Health and Visits for Check-ups

\begin{tabular}{|c|c|c|c|}
\hline \multirow{2}{*}{ Health } & \multicolumn{2}{|c|}{ Go for check ups } & \multirow{2}{*}{ Total } \\
\cline { 2 - 3 } & No & Yes & \\
\hline Very bad & 4 & 0 & 4 \\
\hline Bad & 8 & 5 & 13 \\
\hline Fair & 72 & 18 & 90 \\
\hline Good & 233 & 33 & 266 \\
\hline Very good & 84 & 43 & 127 \\
\hline Total & 401 & 99 & 500 \\
\hline & Value & df & Asymp. Sig. (2-sided) \\
\hline Pearson Chi-Square & 28.805 & 4 & .000 \\
\hline Likelihood Ratio & 28.172 & 4 & .000 \\
\hline
\end{tabular}


with a $p$-value $=0.000$ which is less than the significance level of $5 \%$. This indicates a significant association between online jobs and hours of internet usage.

\subsection{Health of an Individual and Visits for Check-ups}

The results, as evident from Table 4, show a Pearson Chi-Square value of

Table 5: Age and Social Interaction on the Internet

\begin{tabular}{|c|c|c|c|}
\hline \multirow{2}{*}{ Age/ yrs } & \multicolumn{2}{|c|}{ Most of Social interaction on Internet } & \multirow{2}{*}{ Total } \\
\cline { 2 - 3 } & No & Yes & 135 \\
\hline $11-20$ & 31 & 104 & 334 \\
\hline $21-30$ & 97 & 237 & 21 \\
\hline $31-40$ & 14 & 7 & 5 \\
\hline $41-50$ & 4 & 1 & 3 \\
\hline $51-60$ & 3 & 0 & 498 \\
\hline Total & 149 & 349 & Asymp. Sig. (2-sided) \\
\hline & Value & df & .000 \\
\hline Pearson Chi-Square & 29.770 & 4 & .000 \\
\hline Likelihood Ratio & 28.032 & 4 & \\
\hline
\end{tabular}

with a p-value $=0.000$ which is less than the significance level of $5 \%$. This indicates a significant association between regular visits to doctor for check-ups and the health of an individual.

\subsection{Age and Social Interaction on the Internet}

Table 6: Internet and Social Activity

\begin{tabular}{|c|c|c|c|c|c|}
\hline \multirow{2}{*}{$\begin{array}{c}\text { Do you use in- } \\
\text { ternet for social } \\
\text { activities }\end{array}$} & daily & Once a week & monthly & $\begin{array}{c}\text { After } \\
\text { 3-4months }\end{array}$ & \\
\cline { 2 - 6 } & 13 & 23 & 16 & 15 & 67 \\
\hline No & 44 & 120 & 177 & 91 & 432 \\
\hline Yes & 57 & 143 & 193 & 106 & 499 \\
\hline Total & Value & df & \multicolumn{3}{|c|}{ Asymp. Sig. (2-sided) } \\
\hline $\begin{array}{c}\text { Pearson Chi- } \\
\text { Square }\end{array}$ & 9.615 & 4 & \multicolumn{3}{|c|}{.047} \\
\hline Likelihood Ratio & 9.532 & 4 & \multicolumn{3}{|c}{.049} \\
\hline
\end{tabular}


The results, as evident from Table 5, show a Pearson Chi-Square value of with a $\mathrm{p}$-value $=0.000$ which is less than the significance level of $5 \%$. This indicates a significant association between age and social interaction on the internet.

\subsection{Internet and Social Activity}

Table 7: Health Condition and Internet Usage for Treatment

\begin{tabular}{|c|c|c|c|c|}
\hline \multirow{2}{*}{ Health range } & \multicolumn{3}{|c|}{ Does it Solve Problem } & \multirow{2}{*}{ Total } \\
\cline { 2 - 4 } & Never & Sometimes & Always & \\
\hline Very Bad & 1 & 0 & 0 & 1 \\
\hline Bad & 1 & 3 & 4 & 8 \\
\hline Fair & 2 & 20 & 28 & 50 \\
\hline Good & 2 & 59 & 87 & 148 \\
\hline Very Good & 3 & 28 & 32 & 63 \\
\hline Total & 9 & 110 & 151 & 270 \\
\hline & Value & \multicolumn{3}{|c|}{ Asymp. Sig. (2-sided) } \\
\hline Pearson Chi-Square & 34.04 & .000 \\
\hline
\end{tabular}

The results, as evident from Table 6, show a Pearson Chi-Square value of with a $\mathrm{p}$-value $=0.047$ which is less than the significance level of $5 \%$. This indicates a significant association between internet usage by an individual and his/her likelihood of becoming social.

\subsection{Health Condition and Internet Usage for Treatment}

The results, as evident from Table 7, show a Pearson Chi-Square value of with a $\mathrm{p}$-value $=0.000$ which is less than the significance level of $5 \%$. This indicates a significant association between internet usage by an individual and his/her likelihood of finding treatment for health issues.

\section{Discussion of Results}

\subsection{Age}

The analysis reached a conclusion that age has a significant relationship with the amount of internet used on daily basis, with increasing age the internet usage by people drops, thus showing that people from 11-30 yrs of age use more internet and the average daily usage keeps falling with increasing age. 
Akman \& Mishra (2010) survey reached the same conclusion that the age of employees had a significant relation with the average usage of dailyinternet in Turkey. A similar conclusion by Koyuncu \& Lien (2003) found that age promotes online activities and recorded significant positive effects for age. Teo and Lim (2000), Hills and Argyle (2003) surveys reached the conclusion that majority users of internet are young. Jackson et al. (2008), also supported the conclusion; younger Chinese children use internet and computer more and are better at it than older ones.

Middleton, Veenhof, and Leith (2010) found age to be strongly associated with internet use, while the scope of use declined with age. The Future of the (Internet Economy A Statistical Profile (2008) and Jackson et al. (2000) reached the conclusion that elderly people are not used to the penetration of internet into their daily lives as much as the younger generation thus supporting the conlusion that age has a negative relation with avergae usage of internet.

The conclusion also carries a notable trend in the society where the younger generation is more prone to using advancing technology and World Wide Web is integrated to almost all of these in the present era thus making the younger lot a major consumer of internet and making age a significant variable of the study.

\subsection{Expenditure on Internet and Income of User}

The analysis reached the conclusion that people with higher income spend more on the internet they are consuming where the expenditure made was recorded through the service package they bought: thus with increasing income the internet users buy better and more expensive data packages.

A survey of OECD in 2008 revealed that the access of internet is highest in households where the bracket of income was also higher, thus representing a significance between the expenditure on internet by a user and their internet consumption. Akman and Mishra (2010) reached a similar conclusion where the average daily internet usage held a significant relation to the income of the user, thus supporting the reports conclusion. Smith, et al., (2008) concluded that higher the income of someone the more confident they are in spending it on internet in NewZealand, thus supporting the significance of variables.

Kalmus, Realo, and Siibak (2011) support the conclusion that people from a higher income bracket are more involved in internet, thus spending more portion of their income on their daily internet. Jansen (2010) also found the same about the american population i.e. the better-off americans use internet more and so spend more on it.

\subsection{Productiveness of Searches about Health Queries Online}


The results showed a positive relation between the rate of success to gather information about health and the health of a person, thus people with a success rate at the online health query searches are more healthier than those who either don't use internet for these information or do not find the right information on web. Therefore health literacy makes a person healthier. The results were compiled by Andreassen et al. (2007) where they concluded that internet had a direct and positive relation to the health of subjects; are a similar conclusion to this report.

\subsection{Impact of Online Jobs}

The report showed a significance between owning an online job and using more internet while the relation had a positive coefficient thus showing that with more and more online jobs the usage of internet will increase; the conclusion reached has a very logical explanation to it where getting hired in an online job requires first for you to be online.

\subsection{Users of Web Forum}

The analysis reached a significance between the age of users and the usage of social websites, where the nature of the relation was negative thus with increasing age the use of social web forums is reduced, the distribution of sample showed that from a sample of 500 respondents a total of 469 people who used internet belonged to ages 11-30 yrs while the highest rate of usage was noted between people aging from 21-30 yrs.

Smith and Brenner (2012) reported through the Pew Internet Civic Engagement Tracking Survey, established the fact that about $69 \%$ adults online use social websites where as out of 351 sampled people from age $18-29 \mathrm{yrs} 92 \%$ claimed to be using social web forums. Also, $26 \%$ of users of social websites were between the ages 25-34 while $25 \%$ users were between ages $35-44$ while $16 \%$ users in the US social networking were between ages 18-24.

Seybert and Loof (2010) surveyed that out of ten, eight young internet users post to chat sites blogs or social websites, where the people most involved in social interactions online was between ages 16-24 years. Zickuhr and Madden (2011) found that out of ten eight social networkers are of ages 18-29 as compared to seven in ten 30-49 year olds, while only a half of 50-64 year olds, and only a one-third of age 65 and older are involved in social networking online. Lennon et al. (2011) reported that $85 \%$ of participants of survey used social websites weekly while a total of $40 \%$ use it several times a day and this group was dominated by female and people below age 21 .

\subsection{Internet and Social Life}


The analysis concluded that people are more satisfied with their social lives when their most of interaction is on the internet this included social websites, chat forums and other communicating sites. Lennon et al. (2011) reported that people between ages 22-29 give more importance to social networking where the reasons behind it were stated as making new connections with new people and reconnecting with those they have lost touch with and being able to share their lives with people.

Kalmus et al. (2011) through factor analysis of online activities reached two motives behind internet use, one was the social media and entertainment where general linear modelling predicated that the younger age is more involved in the social media online and the second motive behind internet use is work and information where this was more frequent in users of higher educational level and by people at work. Smith and Brenner (2012) in the pew survey about social networking sites exlpored peoples overall relation to these social networks; where the survey found that social netoworking sites are increasingly used to keep up with close social ties while on an average user of social sites have better social circle and are half likely to be isolated as the avergae american. The report also concluded that internet users get more support from these online ties and get closer to their friends and family and revive dormant relations.

Lewin (2008) wrote about a study conducted by MacArthur Foundation in the new york times about teenagers socializing on internet; the study reached a conclusion that it might not be bad after all for teenagers to use internet, though a sample of 800 young people with teenagers socializing online, this has lead to new relations, making ties closer, new romantic relationships are being explored. This socializing is leading to better realtionships in the present on the go system thus better for the social growth of individuals. Lenhart, Purcell, Smith, and Zickuhr (2010) through two pew surveys showed that nearly a $73 \%$ of online teenagers are involved in social networking here the report pointed out the fact that teenagers who are communicating their lives and updating their social circle online have become central activites on these sites and are satisfing its users.

\section{Conclusion}

This paper reviewed and reported the findings of survey concerning the impact of age, income and having an online job on the average daily usage of a person in Pakistan. It includes findings about the social scenario online, representing the age of users involved in the social scene and the satisfaction involved in using these online social sites. The survey was conducted in random patterns in different cities of the country where people from all walks of life were questioned. A total of 500 responses were gathered and was run through analysis. The results indicated that age had a highly 
significant and negative relation with internet usage thus increasing age represented falling average daily usage, while expenditure on internet was directly significant to the income of user and having an online job meant more internet hours used on the average. The analysis showed that the social scene online was dominated by youngsters and that this trend was increasing social satisfaction among its users.

The analysis reached the conclusion that internet usage was strongly influenced by certain demographic factors; Age being on the top, where with increasing age the average internet usage daily kept decreasing, the most frequent users were recorded to be in ages 11-30 years; while another important factor was the income of a user, where with increasing income of people their expenditure on internet increases. The report also concluded that having an online job significantly increased your average usage of internet. The Social media scenario in the report concluded that Age of users was the most important factor in the currently increasing social scene, where people between ages 11-30 years were the major users of Social-Networks while this increasing usage had also reached a satisfaction point to its users; people felt more social when interacting with people on these social forums thus making them satisfied with their social lives.

\section{References}

Akman, I., \& Mishra, A. (2010). Gender, age and income differences in internet usage among employees in organizations. Computers in Human Behavior, 26(3), 482-490.

Andreassen, H. K., Bujnowska-Fedak, M. M., Chronaki, C. E., Dumitru, R. C., Pudule, I., Santana, S., Voss, H., \& Wynn, R. (2007). European citizens' use of E-health services: A study of seven countries. BMC public health, 7, 53.

Hashim, J. (2015). Information communication technology (ICT) adoption among SME owners in Malaysia. International Journal of Business and Information, 2(2), 221-240.

Hills, P., \& Argyle, M. (2003). Uses of the internet and their relationships with individual differences in personality. Computers in Human Behavior, 19(1), 59-70.

Heo, J., Oh, J., Subramanian, S. V., Kim, Y., \& Kawachi, I. (2014). Addictive internet use among Korean adolescents: A national survey. PLoS One, 9(2), 1-8.

Jackson, L. A., Zhao, Y., Qiu, W., Kolenic, A., Fitzgerald, H. E., Harold, R., \& von Eye, A. (2008). Culture, gender and information technology use: A comparison of Chinese and US children. Computers in Human Behavior, 24(6), 2817-2829.

Jansen, B. J. (2010). Use of the internet in higher-income households. Washington, DC: Pew Research Center.

Kalmus, V., Realo, A., \& Siibak, A. (2011). Motives for internet use and their relationships with per- 
sonality traits and socio-demographic factors. Trames, 15(65/60), 385-403.

Koyuncu, C., \& Lien, D. (2003). E-commerce and consumer's purchasing behaviour. Applied Economics, 35(6), 721-726.

Kontos, E., Blake, K. D., Chou, W. Y. S., \& Prestin, A. (2014). Predictors of eHealth usage: Insights on the digital divide from the Health Information National Trends Survey 2012. Journal of Medical Internet Research, 16(7), e172.

Kuss, D. J., Van Rooij, A. J., Shorter, G. W., Griffiths, M. D., \& van de Mheen, D. (2013). Internet addiction in adolescents: Prevalence and risk factors. Computers in Human Behavior, 29(5), 1987-1996.

Lennon, R., Rentfro, R. W., \& Curran, J. M. (2012). Exploring relationships between demographic variables and social networking use. Journal of Management and Marketing Research, 11, 1-16.

Lenhart, A., Purcell, K., Smith, A., \& Zickuhr, K. (2010). Social media $\mathcal{E}$ mobile internet use among teens and young adults. Millennials. Pew Internet \& American Life Project.

Lewin, T. (2008, November 19). Teenagers' internet socializing not a bad thing. The New York Times. Retrieved from http://www.nytimes.com/2008/11/20/us/20internet.html

Middleton, C. A., Veenhof, B., \& Leith, J. (2010). Intensity of internet use in Canada: Understanding different types of users. Statistics Canada. Business Special Surveys and Technology Statistics Division.

Nadkarni, A., \& Hofmann, S. G. (2012). Why do people use Facebook? Personality and individual differences, 52(3), 243-249.

Ngai, E. W., Tao, S. S., \& Moon, K. K. (2015). Social media research: Theories, constructs, and conceptual frameworks. International Journal of Information Management, 35(1), 33-44.

Neter, E., \& Brainin, E. (2012). e Health literacy: Extending the digital divide to the realm of health information. J Med Internet Res, 14(1), e19.

Pearce, K. E., \& Rice, R. E. (2013). Digital divides from access to activities: Comparing mobile and personal computer internet users. Journal of Communication, 63(4), 721-744.

Pontes, H. M., Szabo, A., \& Griffiths, M. D. (2015). The impact of internet-based specific activities on the perceptions of internet addiction, quality of life, and excessive usage: A cross-sectional study. Addictive Behaviors Reports, 1, 19-25.

Ritzhaupt, A. D., Liu, F., Dawson, K., \& Barron, A. E. (2013). Differences in student information and communication technology literacy based on socio-economic status, ethnicity, and gender: Evidence of a digital divide in Florida schools. Journal of Research on Technology in Education, 45(4), 291-307.

Seybert, H., \& Lööf, A. (2010). Internet usage in 2010 - households and individuals. Eurostat Data in focus.

Smith, A., \& Brenner, J. (2012). Twitter use 2012. Pew Internet \& American Life Project

Smith, P., Smith, N., Sherman, K., Kripalani, K., Goodwin, I., Crothers, C., \& Bell, A. (2008). The inter- 
net: Social and demographic impacts in Aotearoa New Zealand. Observatorio (OBS), Journal, 307-330.

Sui, D., Goodchild, M., \& Elwood, S. (2013). Volunteered geographic information, the exaflood, and the growing digital divide. In D. Sui, S. Elwood \& M. Goodchild (Eds.), Crowdsourcing geographic knowledge. (pp. 1-12). Netherlands, Springer.

Tran, H. (2013). Does exposure to online media matter? The knowledge gap and the mediating role of news use. International Journal of Communication, 7, 831-852.

Terlutter, R., Bidmon, S., \& Röttl, J. (2014). Who uses physician-rating websites? Differences in sociodemographic variables, psychographic variables, and health status of users and nonusers of physician-rating websites. Journal of medical Internet research, 16(3), e97.

Teo, T. S., \& Lim, V. K. (2000). Gender differences in internet usage and task preferences. Behavior $\mathcal{E}$ Information Technology, 19(4), 283-295.

Van Deursen, A. J., \& Van Dijk, J. A. (2014). The digital divide shifts to differences in usage. New media E⿱ society, 16(3), 507-526.

Zhang, X. (2013). Income disparity and digital divide: The internet consumption model and cross-country empirical research. Telecommunications Policy, 37(6), 515-529.

Zickuhr, K., \& Madden, M. (2012). Older adults and internet use. Pew Internet \& American Life Project. 
